\title{
The Brain of the Planarian as the Ancestor of the Human Brain
}

\author{
Harvey B. Sarnat and Martin G. Netsky
}

\begin{abstract}
The planarian is the simplest living animal having a body plan of bilateral symmetry and cephalization. The brain of these free-living flatworms is a bilobed structure with a cortex of nerve cells and a core of nerve fibres including some that decussate to form commissures. Special sensory input from chemoreceptors, photoreceptor cells of primitive eyes, and tactile receptors are integrated to provide motor responses of the entire body, and local reflexes. Many morphological, electrophysiological, and pharmacological features of planarian neurons, as well as synaptic organization, are reminiscent of the vertebrate brain. Multipolar neurons and dendritic spines are rare in higher invertebrates, but are found in the planarian. Several neurotransmitter substances identified in the human brain also occur in the planarian nervous system. The planarian evolved before the divergence of the phylogenetic line leading to vertebrates. This simple worm therefore is suggested as a living example of the early evolution of the vertebrate brain. An extraordinary plasticity and regenerative capacity, and sensitivity to neurotoxins, provide unique opportunities for studying the reorganization of the nervous system after injury. Study of this simple organism may also contribute to a better understanding of the evolution of the human nervous system.
\end{abstract}

RÉSUMÉ: Le cerveau de la planaire comme le prototype ancestral du cerveau humain La planaire est l'animal vivant le plus simple montrant une organisation corporelle de la symétrie bilatérale et de la céphalisation. Le cerveau de ces vers plats non parasitaires est une structure bilobée qui comprend un cortex de cellules nerveuses et un milieu de fibres nerveuses comprenant quelques décussations forment des commissures. Les entrées spéciales sensorielles des chimiorécepteurs, des cellules photoréceptrices des yeux primitifs et des récepteurs tactiles sont intégrées pour fournir l'activité motrice du corps entier et des réflexes focaux. Beaucoup d'aspects morphologiques, électrophysiologiques et pharmacologiques des neurones de la planaire ainsi que l'organisation synaptique ressemblent à ceux qu'on trouve chez les vertébrés. Des neurones multipolaires et des épines dendritiques, qui sont rares chez les invertébrés plus développés, sont présents chez la planaire. Plusieurs neurotransmetteurs bien identifiés dans le cerveau humain sont aussi démontrés dans le système nerveux de la planaire. Puisque la planaire évolua avant la divergence de la ligne phylogénétique menant aux vertébrés, ce vers simple peut être un exemple vivant de l'évolution primordiale du cerveau des vertébrés. Sa plasticité et sa capacité régénératrice extraordinaires présentent une occasion unique pour l'étude de la réorganisation du système nerveux à la suite d'une blessure, tandis qu'elles contribuent également à la compréhension améliorée du problème évolutionaire de l'origine du système nerveux.

Can. J. Neurol. Sci. 1985; 12:296-302

The origin of vertebrates in general, and of the vertebrate brain in particular, has been problematic in evolutionary theory for more than a century. It is known with certainty only that the earliest species of the Phylum Chordata, including all vertebrates, diverged from their primitive invertebrate ancestor early in the evolution of animal life and before the proliferation of the numerous phyla of highly specialized invertebrates.

'Planarian' is the common name for numerous species of small nonparasitic flatworms (Phylum Platyhelminthes; Class
Turbellaria), widely distributed throughout the world in fresh and salt water and on land. Planarians are a major evolutionary advance over coelenterates of either polypod form such as the hydra, or medusae such as jellyfish, by the development of bilateral symmetry as abody plan instead of radial symmetry, and by cephalization with a rostrocaudal gradient. Equally important evolutionary advances in the planarian include the development of special sensory organs and the aggregation of nerve cells at the anterior end of the animal, rather than a

From the Departments of Paediatrics. Pathology, and Clinical Neurosciences. University of Calgary Faculty of Medicine. Calgary, Alberta (Dr. Sarnat), and the Department of Pathology, Vanderbilt University School of Medicine. Nashville. Tennessee, U.S.A. (Dr. Netsky)

Received February 26, 1985. Accepted in revised form August 30. 1985.

Reprint requests to: Dr. H.B. Sarnat, Alberta Children's Hospital, 1820 Richmond Road S. W., Calgary, Alberta T2T 5C7 
diffuse network of nerve cells and fibres that characterizes the coelenterate nervous system.

The planarian is thus the simplest living animal to possess a brain. It probably has not much changed since the first planarians appeared on Earth more than a billion years ago. Its brain exhibits many characteristics of the vertebrate central nervous system, some of which are not shared by more advanced invertebrates. Because planarians appeared before the evolution of vertebrates, this contemporary animal may offer insight into the earliest phylogenetic development of the vertebrate brain and ultimately that of humans.

\section{Anatomy of the Planarian Nervous System}

Most planarians are less than $1 \mathrm{~cm}$ in length and have only $1 / 5,000,000$ th the mass of the average human adult, yet the ratio of the brain to body weight is similar to that of a rat. ' Few higher invertebrates or nonmammalian vertebrates show such a high cerebral ratio. The proportion of body volume that is head (and brain) in newborn planarians is much greater than in the adult, as with human infants and adults. ${ }^{2}$

Associated with cephalization, the planarian has the beginnings of special sensory organs. Along the margins of the head, but especially concentrated in the 'auricles' (Fig. I) are ciliary neural processes serving as chemoreceptors, their neurons located on the surface of the brain. ${ }^{3}$ The chemoreceptors of mammalian

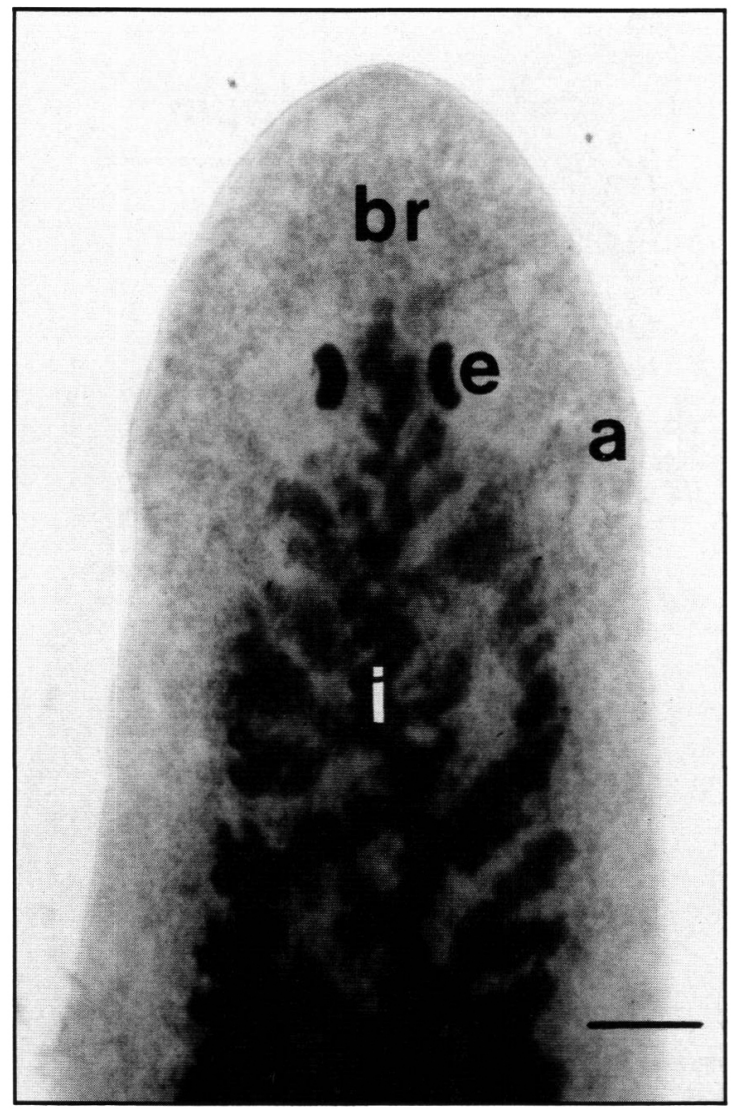

Figure I - Rostral end of the planarian Dugesia tigrina. In this common North American species, the brain (br) is anterior to the eyes (e). The brain is behind the eyes in some species of flatworms. The auricles (a) are lateral extensions of the head with concentrated chemoreceptors, the equivalent of olfactory and gustatory receptors in more complex animals. The irregular dark structure between the eyes is a rostral extension of the intestine (i). Unstained specimen. Bar $=0.5 \mathrm{~mm}$
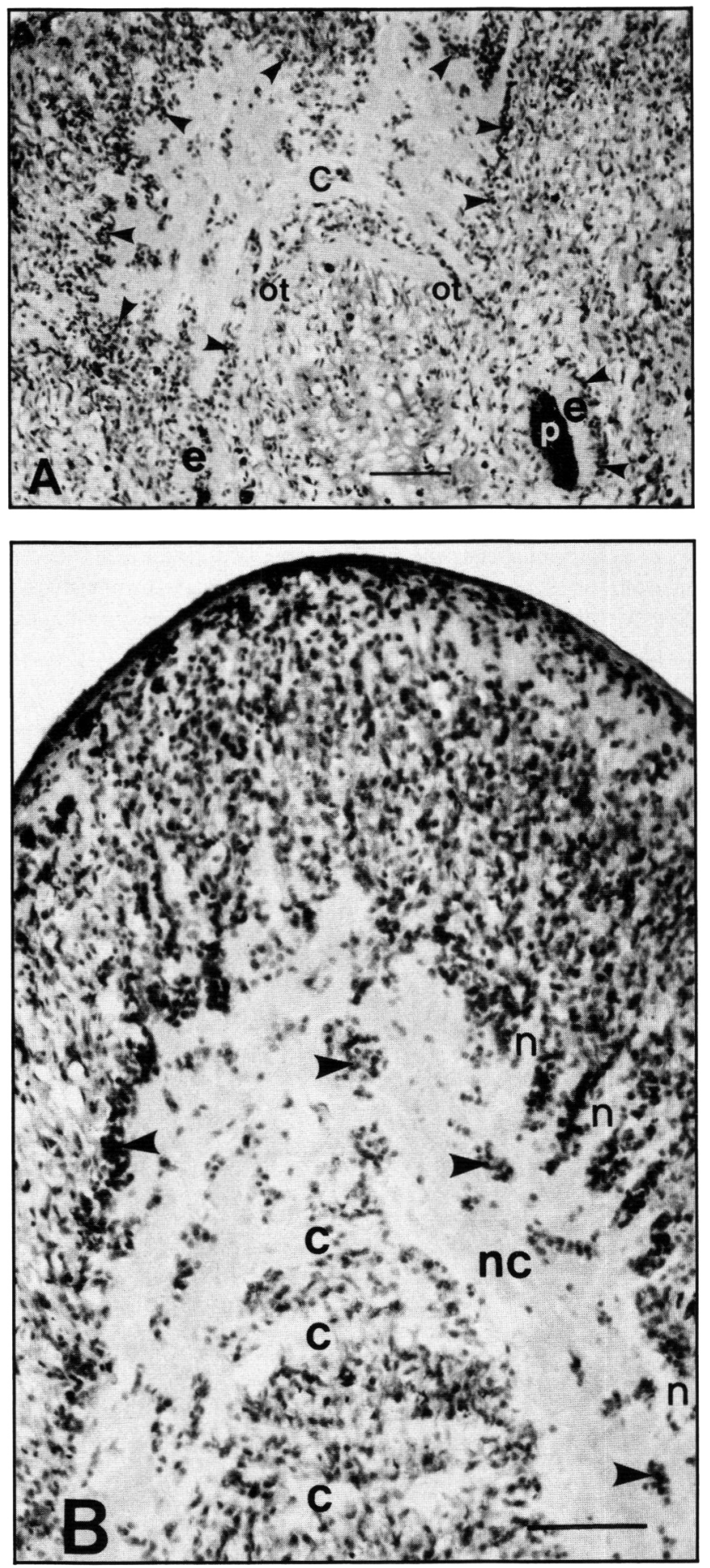

Figure 2 - Frontal section of the planarian brain. (A)In a dorsal plane, optic tracts (ot) extend from the eyes (e) to the brain. Several cerebral commissures (c) are composed of decussating nerve fibres. Neurons (arrowheads) from the surface of the brain ('rind') as a primordial unlaminated cortex, not homologous with mammalian neocortex. Ganglion cells of the eye (arrowheads at lower right) project photoreceptor processes medially toward the pigmented cells ( $p$ ) of the optic cup. (B) In a ventral plane, the brain is caudally continuous with a pair of longitudinal nerve cords (nc) having a structure similar to the brain. Central fibre tracts are surrounded by a cortex of neurons and small clusters of neurons (arrowheads) berween fibre bundles. Commissures (c) interconnect the nerve cords at regular intervals. Sensory and motor nerves $(n)$ emerge together from the cords to form peripheral plexuses. The nerve cords are analogous to the two sides of the spinal cord in vertebrates. Hemotoxylin-eosin. Bars $=200 \mu \mathrm{m}$. 
olfactory neurons are simple naked nerve endings arising from nerve cells of the olfactory bulb, itself a part of the brain. Some planarian species have a statocyst, a rudimentary vestibular organ. ${ }^{4}$ Planarians have a pair of simple eyes.

The planarian brain is bilobed and symmetrical. Large commissures cross the midline to interconnect the two cerebral halves (Fig. 2). Myelin is not formed. Ventricles do not develop and the central core of the cerebrum consists of fibre tracts mixed with small clusters of neurons. Most neurons are situated external to the central 'white matter' as a cortex without lamination, or 'rind' in the terminology of invertebrate zoologists (Fig. 2A). The ventral part of the brain extends posteriorly on each side to become a pair of 'nerve cords' coursing the length of the animal and having a structure similar to that of the brain itself: fibres surrounded by neurons (Fig. 2B). A few large longitudinal nerve fibres within these cords provide for rapid conduction from head to tail, ${ }^{5}$ analogous to the giant cells of Rhode in amphioxus, the pair of large Mauthner cells in the medulla of fishes, and the corticospinal tracts in mammals. ${ }^{6}$ Sensory fibres also ascend to the brain within these cords. The

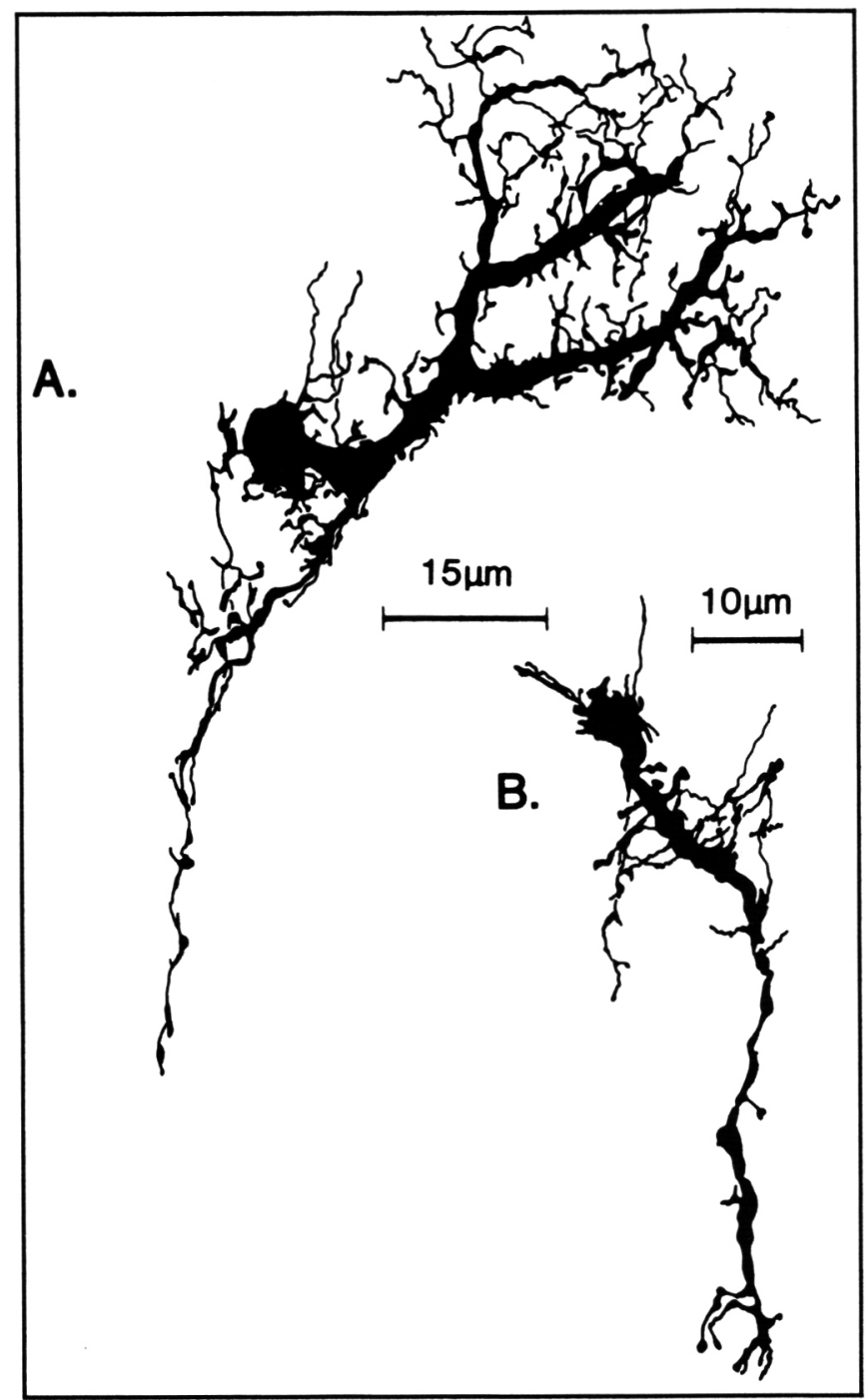

Figure 3 - Drawings from Golgi impregnations of two multipolar cells $(A, B)$ and a stubby dendritic branch with extensive spines $(C)$ of a bipolar neuron in the brain of a marine flatworm of the Order Polycladida. Most planarian neurons have morphological characteristics, such as multipo- pair of nerve cords in the planarian is interconnected at regular intervals by commissures. Peripheral nerve fibres extend from the cords to form subepidermal and submuscular plexuses throughout the body, but peripheral ganglia do not develop. The two nerve cords are thus equivalent to the two sides of the vertebrate spinal cord. In some species, particularly of the more primitive orders, the longitudinal nerve cords are multiple rather than a single pair.

The individual neurons of the planarian brain are as important an advance in evolution as the degree of nervous system organization. Golgi silver impregnations and intracellular injection of fluorescent dyes to fill neuronal processes leads to the conclusion that planarian neurons more closely resemble the neurons of vertebrates than those of higher invertebrates. ${ }^{7.8}$ Among the higher invertebrates, most neurons are unipolar, similar to the dorsal root ganglion cells of vertebrates. The soma is separated from the process by a stalk and does not participate in the propagation of electrical impulses. In the planarian and in all vertebrates, by contrast, typical nerve cells (Fig. 3) exhibit a soma interposed between dendrites and axon;

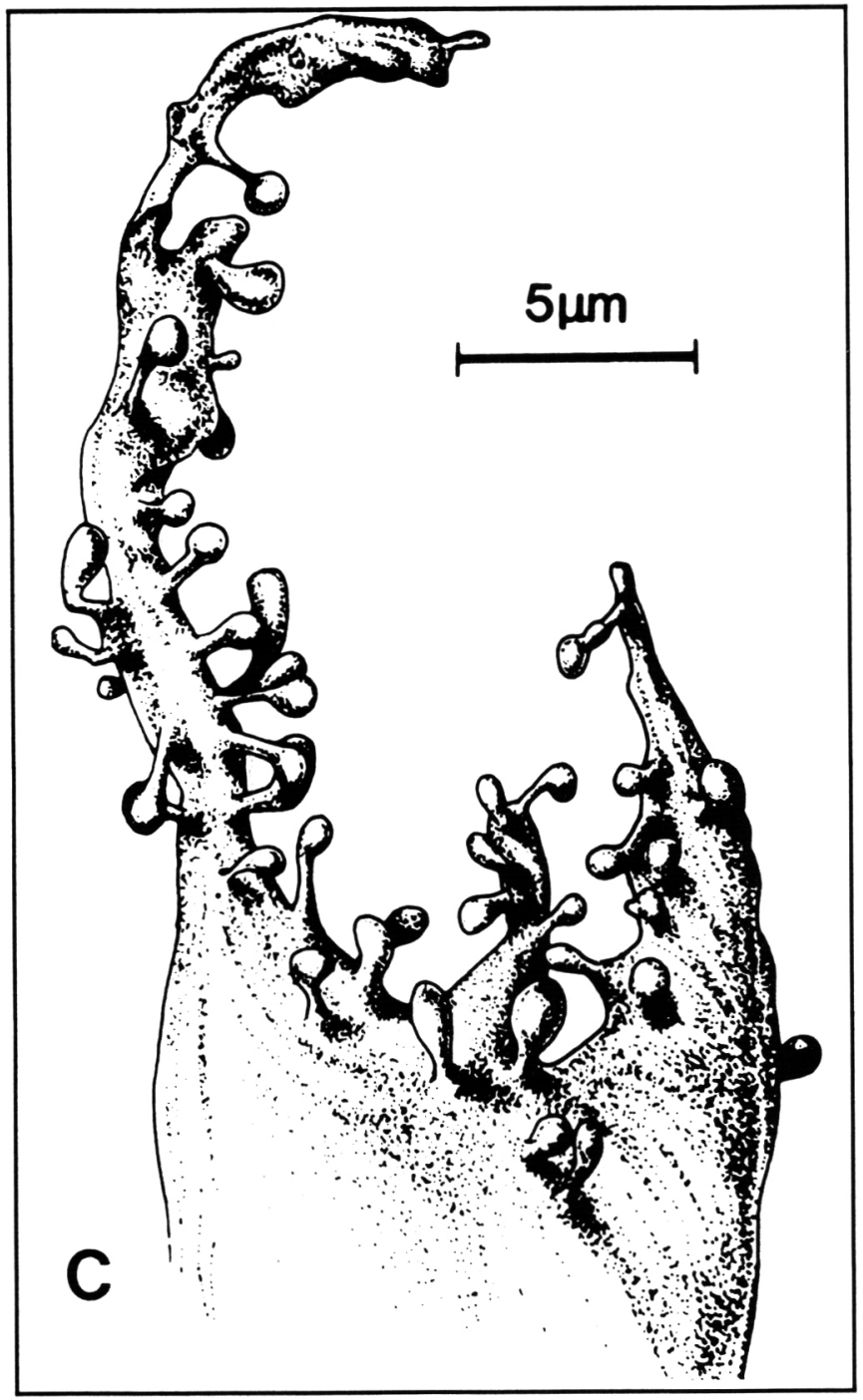

lar processes, dendritic spines, and a single axon, typical of human and other vertebrate neurons, but rare among higher invertebrates. Reproduced from Kennan et al' ${ }^{7}$ with permission of Alan R. Liss, Inc., Publisher. 
multipolar nerve cells are the most common form of neuron in the vertebrate brain, and also are abundant in the planarian. Further examination of planarian neurons reveals that each cell has a single process specialized as an axon, providing for unidirectional flow of the depolarization wave away from the cell body. This typical vertebrate feature is unusual among the advanced invertebrates, whose nerve cells often have two or more axons. ${ }^{4}$ Another vertebrate-like feature of planarian neurons found only rarely in higher invertebrates is dendritic spines, or at least knob-like protrusions along dendrites resembling dendritic spines. ${ }^{4.7}$

Neurons whose axons cross the midline in the planarian brain are of special interest. A phylogenetic hypothesis to explain crossed cerebral control in vertebrates was proposed by us, exemplified by the amphioxus, a primitive protochordate (pre-vertebrate) as a model of cerebral organization. ${ }^{6}$ The decussating interneurons of amphioxus (cells of Rhode) subserve the defensive coiling reflex away from a threatened side. The theory may now be extended even earlier in phylogeny to originate with the planarian brain. Not only are decussating interneurons demonstrated anatomically in the planarian, but removal of half the brain or commissurotomy results in hemiparesis of the opposite side of the body. ${ }^{9}$

Cells reminiscent of the specialized neurosecretory cells of the hypothalamus and neurohypophysis of vertebrates also are detected in the planarian brain..$^{5.10-12}$ These neurosecretory cells are situated near the entrance of the optic tracts into the brain, as with vertebrates but also at a similar site in the brains of annelids, molluscs, crustaceans, and insects. At least two different systems of neurosecretory cells can be distinguished in the planarian, on the basis of ultrastructural morphology. The secretory cells change in appearance and number with sexual maturation and during regeneration after bodily injury. ${ }^{13}$ Melatonin is released and is involved in a day-night rhythm of fissioning (asexual reproduction), interrupted by continuous illumination, by continuous darkness, or by decerebration. ${ }^{14}$

The planarian brain also contains small multipolar nonelectrical glial cells similar to primitive astrocytes. ${ }^{5.7}$ The more advanced species of planarians have a connective tissue capsule enclosing the brain, reminiscent of meninges and cranium.

\section{Synaptic organization of the planarian brain}

Synaptic junctions develop in the planarian as modifications of receptor membrane surfaces, associated with neurosecretory products becoming concentrated in vesicles at the axonal tip. Histochemical and pharmacological studies demonstrate that various planarian neurons contain norepinephrine, epinephrine, serotonin, and acetylcholine, ${ }^{5,10,11,16-18}$ substances also serving as neurotransmitters in all higher animals. Several mammalian neuropeptides also occur in the planarian, as well as in some higher invertebrates such as annelids. Ultrastructural studies of the planarian brain confirm the presence of synaptic vesicles of at least three morphological varieties originating from Golgi membranes, and of chemical synaptic junctions in the neuropil. ${ }^{5,11.19 .20}$ Axoaxonal as well as axodendritic synapses are demonstrated, although axosomatic junctions have not been found. ${ }^{5}$ Both excitatory and inhibitory effects are recorded electrophysiologically in the nerve cords of flatworms. ${ }^{21}$ Glycine and gamma-aminobutyric acid (GABA), both inhibitory neurotransmitters in vertebrates, have a pronounced depressant influence on the planarian nervous system. ${ }^{22}$ Electrotonic 'tight junction' synapses without chemical transmitters also are found, and are abundant in other simple species of both vertebrates and invertebrates.

\section{Electrophysiology of the planarian brain}

Vertebrates and invertebrates differ fundamentally in the character of spontaneous electrical activity generated by both individual neurons and by neuronal circuits. Vertebrates, whether fishes, reptiles, or primates, produce predominantly slow wave rhythmic activity of less than $50 \mathrm{~Hz}$ and mainly less than 10 $\mathrm{Hz}$,associated with few spikes. Recordings from the ganglia and brains of invertebrates such as the lobster and various insects show almost continuous rapid spike activity several hundred $\mathrm{Hz}$ in frequency, and very little slow wave activity. ${ }^{4}$ This paucity of slow waves perhaps is related to the less branched, spineless dendrites arising from typical invertebrate neurons, since slow waves of vertebrates correlate with ramification of dendrites and proliferation of axodendritic synapses.

Polyclad flatworms, the planarians with the most complex nervous systems, have cerebral neurons also generating spontaneous potentials of both spikes and waves as well as a considerable amount of slow activity, as is characteristic of vertebrate nervous systems. ${ }^{23}$ Inhibitory effect on the nerve cords by increasing intensity of electrical stimulation is abolished if the brain is bisected by commissurotomy, ${ }^{21}$ analogous to the release from inhibition in the human spinal cord if the pyramidal tract or the contralateral motor cortex is damaged.

Interneurons in the planarian are either spiking or silent, as found in higher animals; habituation is demonstrated just as in the central nervous system of vertebrates. ${ }^{9}$ This phenomenon involves changes in the ability of the postsynaptic membrane to carry a charge.

It has already been mentioned that multipolar neurons appear for the first time in evolution in the planarian brain. These vertebrate-like multipolarneurons exhibit tetrodotoxin-sensitive and voltage-gated fast sodium channels for rapid depolarization of the cell membrane, another major advance first developed in the planarian.

\section{The planarian eye}

The pair of planarian eyes is dismissed by most authors of biology textbooks and other scholarly works as mere 'eyespots', yet these organs have remarkable features of primordial true eyes even if a complete globe is not formed (Fig. 4). A cornea of transparent epithelial cells overlies each eye. The photoreceptor processes face a cup of melanin-containing cells, similar to the pigmented choroid of the vertebrate eye, for the purpose of reducing reflection and scatter of bright light. Each of the two planarian eyes is "suspended in a cradle of fine muscle fibres suggestive of some degree of directional control . ..". In some species, these muscle fibres are grouped and firmly attached to the pigmented optic cupexternally, ${ }^{24}$ resembling the extraocular muscles of more evolved species (Fig. 4).

Axons of photoreceptor ganglion cells form a large optic tract on each side and enter the brain (Fig. 2A). A few efferent nerve fibres projecting from the brain also synapse onto the photoreceptor cells, their probable function being to modulate the sensitivity of these nerve cells in relation to changes in the intensity of ambient light. ${ }^{25.26}$ The planarian eye is capable of dark adaptation. ${ }^{24.26}$ One feature of the planarian photoreceptor cell differs from its counterpart in the vertebrate retina: the 


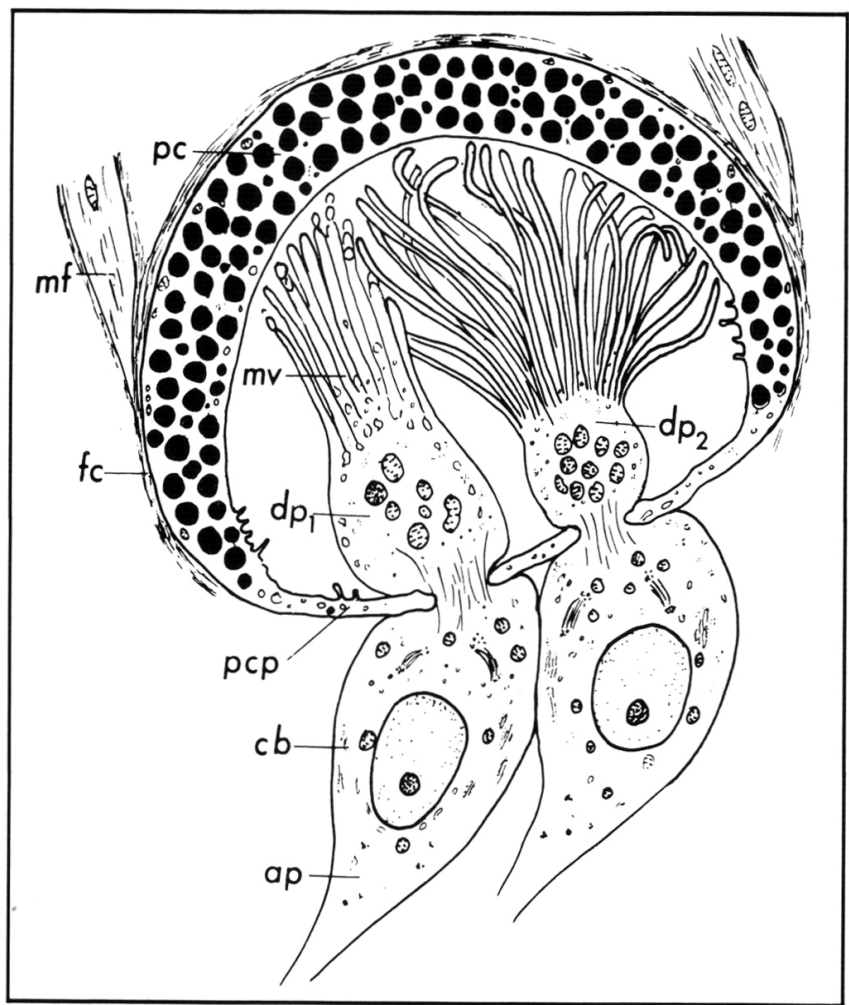

Figure 4 - Illustration of the eye of a marine species of flatworm, the simplest form of the eye among living animals. An optic cup consists of pigment cells $(p c)$ surrounded by a fibrous capsule $(f c)$ to which muscle fibres $(\mathrm{mf})$ are attached. The nucleated cell body $(c b)$ of the ganglion cell (only two illustrated) has an axonal process (ap) projecting to the brain, and a dendrite penetrating pigment cell projections ( $p c p$ ) of the optic cup to terminate as photoreceptor microvilli (mv). Dark-adapted photoreceptor dendrites $\left(d p_{l}\right)$ have shorter microvilli, more numerous vacuoles, and altered mitochondria, in comparison with non-dark-adapted photoreceptors $\left(d p_{2}\right)$. Reproduced from MacRae ${ }^{24}$ with permission of Springer-Verlag.

light-sensitive processes are specialized microvilli of the cell membrane (rhabdomeres) rather than specialized cilia ${ }^{24.27 .28}$ in this respect more similar to the higher invertebrates.

\section{Planarian muscle}

The somatic muscles of the planarian are unstriated, but this condition is a primitive state preceding the differentiation of muscle into smooth and striated varieties, rather than being mature visceral muscle. ${ }^{29}$

\section{Regenerative capacity of the nervous system}

The planarian is probably best known to students of biology because of its extraordinary regenerative abilities. Abundant totipotential 'neoblasts' are the bulk of the undifferentiated mesenchyme between formed organs in the adult animal. If the individual is decapitated, it grows a new head and brain within a week or two; if the head is sagittally divided, the two halves each regenerate into a complete head and brain. The twoheaded animal eventually completes body fission to form two whole individuals. ${ }^{30}$ If one lobe of the brain is selectively excised in marine flatworms, however, it does not regenerate but rather cranial nerves from the brainless side grow across the midline to become reconnected to the remaining half-brain, and the animal seems to behave normally again. ${ }^{23}$
The implications of this plasticity for experimental regeneration in the human nervous system are numerous, particularly in view of the vertebratelike features of planarian neurons.

\section{Behaviour of planarians and the effects of cerebral lesions}

The brain of the planarian controls coordination and behaviour as in higher animals. If the brain is bisected, the worm no longer is able to perform avoidance turning. ${ }^{9}$ Conditioned reflexes are lost after removal of the brain. ${ }^{4}$ Decerebrate planaria show paucity of locomotion and loss of coordination, with abolition of the normal alternation of extension of left and right sides of the body, and posteriorly propagated swimming movements; dorsoventral righting reflexes and orientation toward food are also severely impaired. Uncoordinated feeding occurs if contact is made with food, but satiety does not inhibit further feeding as it does in the intact state. Decerebrate animals have never been observed to copulate, and when eggs are laid, they are never arranged in neat coils as done by normal worms. ${ }^{9}$

Finally, the planarian may actually be capable of learning, or at least of conditioning. ${ }^{4.31-34}$ This simple worm with its vertebrate-like brain ". . . exhibits behaviours . . . more like those of a miniature psychological behaviour system than the rigidly reflexive organism depicted in classical descriptions". ${ }^{32}$

\section{COMMENT}

The many features of the planarian nervous system resembling the nervous system of vertebrates provide a foundation for the hypothesis that this simple worm may be similar phylogenetically to the ancestor of vertebrates. Appearing on Earth long before the first vertebrates, the planarian accomplished major advances in complexity of neural organization over its simpler predecessors. Once these radical innovotions appeared, however, at least some species of planarians subsequently changed little since the Cambrian Era. Some species became parasites, thus evolving the two other classes of flatworms: flukes (Trematoda) and tapeworms (Cestoda), possessing resimplified nervous systems to satisfy fewer needs than the free-living predatory planarians. Still other mutations of early planarians probably evolved into other new phyla of more complex animals and lost their identity as flatworms.

Nemertines are obscure marine 'ribbon worms' that also have survived epochs of geological time. They are familiar to invertebrate zoologists because they are thought to be the most direct descendents of flatworms and are cited as a probable ancestral group giving rise to vertebrates. Nemertines are slightly more complex than planarians in most body systems. They develop a dorsal, fluid-filled, rod-like structure that could have become modified to create a notochord, ${ }^{6.35 .36}$ and they have a bilobed brain containing neurosecretory cells. ${ }^{4}$ Whether nemertines are actually in a line of evolution between planarians and vertebrates is uncertain. It is unlikely that vertebrates originated from one of the modern phyla of complex invertebrates such as annelids, molluscs, or arthropods.

Differences are easy to recognize, but similarities require more critical examination. This principle is particularly evident when comparing the nervous systems of vertebrates with those of the many divergent groups of invertebrates. Eccentric developments digressing from the main evolutionary sequence are found in every species of specialized animal. Such phylogenetic distractions do not render invalid the recognition of fea- 
tures shared by all nervous systems. Segmental organization with a brain exerting rostral control over reflexive patterns for locomotion and feeding is universal. Neurotransmitters used in common by the brains of planarians, insects, octopuses, and humans include acetylcholine, norepinephrine, serotonin, various amino acids, and peptides. The brain produces a simple peptide that causes the secretion of steroid hormones from a remote abdominal gland not only in mammals and other vertebrates, but also in spiders and in other highly evolved invertebrates. Even psychological traits fundamental to survival, such as fear and hunger, are demonstrated in the behaviour of invertebrates. ${ }^{37}$ The hypothesis that the planarian brain is the prototype of the vertebrate brain is not weakened by similarities that are found in comparing the planarian with higher invertebrates.

Many textbooks of general biology still refer to the aggregate of neural tissue in the head of the planarian as a "cephalic ganglion', although other authors recognize that this aggregate fulfills the criteria of a true brain: it is bilobed, symmetrical, and subserves the entire body rather than restricted segments or parts. Most importantly, it contains several types of neurons including interneurons providing for intrinsic multisynaptic circuits. Ganglia are composed almost exclusively of either motor or sensory neurons, each with at least one process extending into the periphery, and providing merely for monosynaptic relay. Commissures of decussating nerve fibres further distinguish a brain from a ganglion.

The major advances in organization of the nervous system exhibited by the planarian are matched by equally impressive evolutionary changes in the individual neuron. The two qualities which together distinguish the neuron from other cells in either ontogenetic of phylogenetic development are an excitable membrane and secretory activity. Muscle cells have electrically polarized, excitable membranes but do not normally secrete chemical substances. Endocrine and some mucosal cells are secretory but the plasma membranes are not excitable. It has been suggested that nerve cells arose from ancestral secretory cells, when the secretory function became confined to the terminations of processes to provide a new role in neurotransmission. ${ }^{38.39}$

Other features of most nerve cells, including the development of axons, dendrites, and synapses, and the propogation of action potentials along processes, are secondary adaptations not essential to identity as neurons. An example of a mature nerve cell lacking these secondary specializations is the chromaffin cell of the human adrenal medulla. These cells retain the potential to develop axons and propagate depolarization waves under experimental conditions, as when autologously transplanted into the brain. ${ }^{40}$ The Phylum Coelenterata, including hydras, sea anemones, and jellyfishes, are the simplest living animals with neurons. These primitive nerve cells have processes, but they are not yet distinguished as dendrites or axons; electrical conduction proceeds in both directions. The neurons are not aggregated and are arranged as a diffuse network. The planarian therefore represents an evolutionary advance from the primitive coelenterate condition as large in magnitude as the divergence of the vertebrates.

The planarian brain is now being used in innovative experiments as a test animal for neurotoxins, particularly in detecting harmful concentrations of environmental pollutants in water.' This use is justified because of the many features of the planar- ian brain reminiscent of the vertebrate condition. The planarian is abundant, easy and inexpensive to maintain in the laboratory, and takes little space (dozens may be kept in a petri dish).

If another mass extinction should occur on Earth, life for humans probably would end as it did for the dinosaurs some 65 million years ago. The resilient planarian would likely survive as it has survived each of the several previous mass extincitions of life known from the fossil record. The plasticity of its primordial brain is extraordinary. Might another billion years of planarian evolution yield an intelligent dinosaur, an intelligent primate, or another yet unknown intelligent species?

\section{ACKNOWLEDGEMENT}

Ms. Yvonne Smink assisted with the technical preparations of planarian brain sections. This work is supported by a research grant to $\mathrm{Dr}$. H.B. Sarnat by the Alberta Children's Hospital Foundation.

\section{REFERENCES}

1. Best JB. Transphyletic animal similarities and predictive toxicology. In: van der Merwe A, ed. Old and New Questions in Physics, Cosmology, Philosophy, and Theoretical Biology. New York: Plenum Press. 1983: 549-591.

2. Heller ZT, Hauser J. Relation between sizes of cocoons of Dugesia shubarti and number and size of eclodid babies. IV Int. Symposium on the Biology of Turbellaria. Fredericton, New Brunswick. Aug. 5-9, 1984.

3. Pigon A, Morita M, Best JB. Cephalic mechanisms for the social control of fissioning in planarians. 11. Localization and identification of the receptors by electronmicrographic and abaltion studies. J Neurobiol 1974; 5: 443-462.

4. Bullock TH. Horridge GA. Structure and Function of the Nervous System of Invertebrates. 2 vols. San Francisco: Freeman. 1965: $14,53,318,535-595,1603-1604$.

5. Morita M, Best JB. Electron microscopic studies of planaria. 111 . Some observations of the fine structure of planarian nervous tissue. J Exp Zool 1966; 161: 391-412.

6. Sarnat HB, Netsky MG. Evolution of the Nervous System. 2nd edition. New York: Oxford University Press. 1981: 10-19:55-58.

7. Keenan CL, Cross R, Koopowitz H. Cytoarchitecture of primitive brains: Golgi studies in flatworms. J Comp Neurol 1981; 195: 697-716.

8. Koopowitz $\mathrm{H}$. The evolution of the nervous system in the turbellaria. IV International Symposium on the Biology of the Turbellaria. Fredericton, New Brunswick. Aug 5-9, 1984.

9. Gruber SA, Ewer DW. Observations on the myo-neural physiology of the polyclad, Planocera gilchristi. J Exp Biol 1962: 39: 459-477.

10. Lender T, Klein N. Mise en évidence de cellules sécrétrices dans le cerveau de la planaire Polycelis nigra. CR Acad Scie Paris 1961: $253 ; 331-333$.

11. Oosaki T, Ishii S. Observations on the ultrastructure of nerve cells in the brain of the planarian Dugesia gonocephala. Ztschr Zellforsch 1965; 66: 782-793.

12. Morita M, Best JB. Electron microscopic studies of planaria. II. Fine structure of the neurosecretory system in the planarian Dugesia dorotocephala. J Ultrastruct Res 1965: 13: 396-408.

13. Lender Th. Endrocrinologie des planaires. Bull Soc Zool Fr 1980: 105: 173-191.

14. Morita M. Best JB. Effects of photoperiods and melatonin on planarian asexual reproduction. J Exp Zool 1984; 231: 273-282.

15. Bullock TH, Nachmansohn D. Cholinesterase in primitive nervous systems. J Cell Comp Physiol 1942; 20: 239-242.

16. Welsh JH, Moorhead M. The quantitative distribution of 5-hydroxytryptamine in the invertebrates, especially in their nervous systems. J Neurochem 1960; 146-169.

17. Lentz TZ. Histochemical localization of acetylcholinesterase activity in a planarian. Comp Biochem Physiol 1968; 27: 715-718.

18. Welsh, JH, Williams LD. Monoamine-containing neurons in planaria. J Comp Neurol 1970; 138: 103-116. 
19. Best JB, Noel J. Complex synaptic configurations in planarian brain. Science 1969;164: 1070-1071.

20. Koopowitz H, Chien P. Ultrastructure of nerve plexuses in flatworms. Il. Sites of synaptic interactions. Cell Tiss Res 1975; 157: 207-216.

21. Koopowitz H, Kennan L, Bernardo K. Primitive nervous systems: Electrophysiology of inhibitory events in flatworm nerve cords. J Neurobiol 1979; 10: 383-395.

22. Keenan L, Koopowitz H, Bernardo K. Action of aminergic drugs and blocking agents in activity in the ventral nerve cord of the flatworm Notoplana acticola. J Neurobiol 1979; 10: 397-407.

23. Koopowitz H. Free-living Platyhelminthes. In: Shelton GAB, ed. Electrical Conduction and Behaviour in 'Simple' Invertebrates. Oxford: Clarendon Press, 1982: 359-392.

24. MacRae EK. Fine structure of photoreceptors in a marine flatworm. Ztschr Zellforsch 1966; 75: 469-484.

25. Carpenter K, Morita M, Best JB. Ultrastructure of the photoreceptor of the planarian Dugesia dorotocephala. I. Normal eye. Cell Tiss Res 1974; 148: 143-158.

26. Carpenter K, Morita M, Best JB. Ultrastructure of the photoreceptor of the planarian Dugesia dorotocephala II. Changes induced by darkness and light. Cytobiologie 1974; 8: 320-338.

27. Röhlich $P$, Török LJ. Elektronenmikroskopische Untersuchangen des Auges von Planarien. Ztschr Zellforsch 1961; 54: 362-381.

28. MacRae EK. Observations on the fine structure of the photoreceptor cell in the planarian Dugesia tigrina. J Ultrastruc Res 1964; 10: 334-349.
29. Sarnat HB. Muscle histochemistry of the planarian Dugesia tigrina (Turbellaria: Tricladida): Implications in the evolution of muscle. $\operatorname{Tr}$ Am Micr Soc 1984; 103: 284-294.

30. Brønsted HV. Planarian Regeneration. Oxford, Toronto: Pergamon Press. 1969: 83-100; 129-136.

31. Best JB, Rubenstein I. Maze learning and associated behaviour in planaria. J Comp Physiol Psychol 1962; 55: 560-566.

32. Best JB, Rubenstein 1 . Environmental familiarity and feeding in a planarian. Science 1962; 135: 916-918.

33. Best JB. Protopsychology. Sci Amer 1963; 208: 54-62 (Feb).

34. Koopowitz $\mathbf{H}$. Feeding behaviour and the role of the brain in the polyclad flatworm, Planocera gilchristi. Anim Behav 1970;18: 31-35.

35. Jensen DD. Hoplonemertines, myxinoids, and deuterostome origins. Nature 1960; 188: 649-650.

36. Willmer EN. The possible contribution of nemertines to the problem of the phylogeny and the protochordates. Symp Zool Soc Lond 1975; 39: 319-345.

37. Dethier V. Microscopic brains. Science 1964; 10: 1138-1145.

38. Clark RB. On the origin of neurosecretory cells. Ann Sci Nat Zool 1956; 18: 199-207.

39. Grundfest $H$. Evolution of electrophysiological properties among sensory receptor systems. In: Pringle JWS, ed. Essays on Physiological Evolution. Oxford: Pergamon Press. 1965: 107-138.

40. Freed WJ, Morishasa JM, Spoor E, et al. Transplanted adrenal chromaffin cells in rat brain reduce lesion-induced rotational behaviour. Nature 1981; 292: 351-352. 